\title{
VALORES DISEMINADOS POR LA MUÑECA BARBIE EN LA PÁGINA WEB BARBIE.COM Y EN FACEBOOK
}

\author{
Pâmela Saunders Uchôa-Craveiro1: Universidad de Vigo. España. \\ pamela_uchoa@yahoo.com.br
}

\section{RESUMEN}

Este trabajo busca identificar los valores comunicados por la muñeca Barbie en la página web española de su marca y medir el grado de identificación de las fans infantiles con la muñeca en Facebook. Se propone discutir la relación de la infancia con el consumo, reflexionar sobre las consecuencias del marketing infantil en la formación de los niños, destacar la importancia de la educación en el desarrollo de niños consciente y con actitudes críticas frente los mensajes transmitidos por los medios de comunicación, así como aportar una contribución al debate sobre cómo y qué estrategias de comunicación están siendo desarrolladas por las compañías de juguetes.

PALABRAS CLAVE: Marketing infantil - Consumo - Infancia - Internet - Barbie

\footnotetext{
${ }^{1}$ Autor correspondiente

Pâmela Saunders Uchôa-Craveiro Universidad de Vigo. Pontevedra (España

Correo: pamela_uchoa@yahoo.com.br
} 


\title{
DISSEMINATED VALUES BY BARBIE DOLL ON THE WEBPAGE BARBIE.COM AND ON FACEBOOK
}

\begin{abstract}
This paper seeks to identify the values reported by the Barbie doll in her Spanish website and to measure the degree of identification of children with Barbie Doll on Facebook. It is proposed to discuss the relationship of children with consumption, to reflect on the consequences of children's marketing in their education, to highlight the importance of education in the children's development as conscious consumers and with critical attitudes in front of themessages transmitted by the media, as well as contributing to the discussion on how and what communication strategies are being developed by the toy companies.
\end{abstract}

KEY WORDS: Children's Marketing - Consumption - Childhood - Internet - Barbie

\section{INTRODUCCIÓN}

Algunos autores sostienen que la infancia no es una categoría biológica, sino una construcción social. Esta idea de que la infancia es una etapa especial que presenta peculiaridades diferentes de la edad adulta no ha existido siempre. El concepto ha cambiado con el paso de los siglos, influenciado por los acontecimientos, costumbres y pensamientos de cada época. De hecho, los niños actuales no son los mismos de hace siglos. Hoy en día tienen más conocimiento sobre tecnología, influyen en las compras de sus padres, son consumidores exigentes, pero una cosa es cierta: no han dejado de ser niños emocionalmente.

La concepción actual de la infancia presenta una ambigüedad, pues a pesar de que presenciemos niños más independientes, activos y que utilizan códigos específicos, la sociedad todavía ve la infancia como un periodo de aprendizaje y formación. El conocimiento impartido por los medios de comunicación de masas - destacando el rol de la televisión y ahora de Internet de manera más contundente - rompe con la autoridad de la familia y de la escuela como instituciones que tienen y controlan los conocimientos transmitidos a los niños. Además, los medios de comunicación transmiten modelos y patrones de comportamiento que influyen en la composición de la identidad de los más jóvenes, dejando, muchas veces, las opiniones de sus padres y profesores en segundo plano. 
Esta nueva generación de niños nació rodeada de medios digitales, siendo así el entorno tecnológico que les rodea puede ser visto como una extensión de ellos mismos. Los niños del siglo XXI no se contentan con ser sólo espectadores, desean participar. La interactividad ${ }^{2}$ es un punto alto entre ellos e Internet es un medio que responde a esta necesidad. Navegar en la Red permite jugar, buscar, comprar, hablar, aprender, conocer gente nueva, hacer preguntas, expresarse, exponer ideas, etc.

Es hecho que los niños han cambiado y no se les puede negar el derecho a serlos agentes económicos. Sin embargo, no se puede ignorar que "el entorno que se ha dado la libertad a los niños está cada vez más dominado por una cultura de consumo que resulta nociva" (Schor, 2004, p. 266). La solución a este problema no es atribuir demasiada responsabilidad al niño que no pueda cumplir, por otro lado no se debe eliminar todas las sus responsabilidades de manera que perjudique su desarrollo.

Las empresas se dieron cuenta que los niños son personas activas, independientes y están adaptando su comunicación a esta nueva generación. Las grandes marcas de productos infantiles están desarrollando acciones de comunicación específicas para estos consumidores.

Las marcas infantiles utilizan diversos medios de comunicación para lograr el lado emocional de los niños, pero este trabajo se concentra en Internet. Busca identificar las estrategias utilizadas por la marca Barbie en la Red para fidelizar las niñas.

Con esta perspectiva hemos querido analizar cómo la marca de juguetes Mattel se comunica con las niñas en Internet, utilizando su personaje virtual Barbie. Para ello, hemos analizado el contenido de la página web barbie.com y el discurso de las niñas fans de la muñeca Barbie en la página oficial de la marca en Facebook.

Hemos buscado con este estudio hacer una reflexión acerca de los valores y símbolos transmitidos a los niños por las marcas de juguetes a través de Internet. Específicamente, la investigación se centró en el análisis de cómo la muñeca virtual Barbie comunica la identidad de su marca y crea un vínculo con sus consumidoras infantiles. En un según momento, hemos optado por observar lo que decían niñas fans de Barbie en Facebook, pues acreditamos que oír lo que ellas piensan sería una manera de comprender lo que es ser una niña en la actualidad. 
Además, pensamos que dar voz a las niñas en este estudio sería una forma de garantizar el derecho a expresar sus opiniones. Siendo así, la escoja de esta metodología ha permitido que las niñas expresaran sus pensamientos sobre la marca Barbie.

\subsection{Breve historia de la muñeca Barbie}

Barbie, en sus 52 años de existencia, se ha convertido en una referencia de belleza para niñas de todas las edades. Puede ser vista como un estereotipo de belleza que las chicas quieren seguir, llevadas a creer que si son como Barbie serán más felices.

Barbie surgió en el periodo posterior a la Segunda Guerra Mundial cuando el parámetro del ama de casa feliz estaba siendo sustituido por un nuevo control social de la mujer: el mito de la belleza (Wolf, 1992). Después de la Segunda Guerra Mundial, la compra de cosméticos creció considerablemente y este ya no era un artículo consumido sólo por el segmento más rico de la población.

Una preocupación por las normas estéticas pasó a ser perseguida por la mayoría de las mujeres que tenían como inspiración las estrellas del cine americano. Por lo tanto, en este contexto de la supervalorización de la apariencia física femenina, Barbie fue presentada a la sociedad como una muñeca adulta, con maquillaje y vestida con ropa de moda. Sus características se inspiraron en las estrellas de cine Catherine Denueve, Hedy Lamarr, Brigitte Bardot y Grace Kelly.

Además, el traje usado por la primera versión de Barbie deriva del modelo utilizado por Grace Kelly en un ensayo fotográfico de 1956. Las características de la primera muñeca (maquillaje blanco, cejas arqueadas, pelo recogido y una postura seria) representaban fielmente a las mujeres de la época.

En los más de 50 años de existencia de la muñeca Barbie, es posible ver la evolución de las mujeres y de las costumbres de nuestra sociedad. También se puede percibir, con el pasar del tiempo, el uso de la muñeca como una referencia de belleza y un estilo de vida centrado en la estética y en el consumismo.

Barbie es un símbolo de la belleza, de la juventud y del éxito, adorada por niños y adultos en todo el mundo. Ha superado el estado de ser sólo una simple muñeca destinada a divertir a las niñas y ha alcanzado el status de personalidad inmortal. Dos pruebas de ello son que su imagen ha sido modelada en el museo de cera de Grévin en Paris y sus huellas grabadas en el paseo de la fama de Hollywood, junto a estrellas como Charles Chaplin y Marilyn Monroe. 
La gran ventaja de Barbie es que no se presenta como un modelo fijo e inalterable. Ella, a través de sus ropas y accesorios, comunica varias personalidades, pudiendo ser romántica, sofisticada, deportiva, inocente, seductora, alegre... Es la niña que decide sobre lo que vestirá la muñeca y que rol desempeñará en el juego. Las imágenes de Barbie se renuevan constantemente para no cansar a los consumidores y para acompañar los posibles cambios en los valores de la sociedad.

Además de ser uno de los juguetes más populares desde el momento de su creación, se convirtió en un icono cultural. Refleja el comportamiento y los deseos de cualquier niña. Puede ser quien desea en su "mundo" de color rosa, donde todo es fácil, divertido, bello, glamuroso y donde sigue las últimas tendencias de la moda. Por su tiempo de fabricación, cantidad de ventas y momento alcanzado, Dominguez y Juste (2005) califican Barbie como el primer juguete globalizado.

Barbie satisface la necesidad natural de toda niña de jugar a ser adulta. No obstante, como su imagen está siempre acompañada de un comportamiento joven y dirigido al consumo, acaba por transmitir a las niñas el mensaje de que ser adulta es ser joven, guapa y consumista como la muñeca. El problema citado por muchos críticos es que limita la imaginación en los juegos de las niñas porque está impregnada de valores que indican lo que es estéticamente preferible.

Sin embargo, no se puede ignorar que existe la posibilidad de que las niñas puedan romper las reglas propuestas de lo que es estéticamente preferible y construir otras identidades para su Barbie. Al darle nuevos roles, nuevos nombres y nuevos contextos, muestran que son libres para otorgar otros significados a sus muñecas.

Cuando las representaciones sugeridas de un juguete son desafiadas por la creatividad de los juegos infantiles, se demuestra que no son innegociables o deterministas (Almeida, Heberle, 2006). Por tanto, es muy importante inculcar y fomentar la creatividad en los niños, de modo que, incluso con los juguetes relacionados con comportamiento consumistas, puedan ejercer su plena libertad para imaginar y fantasear.

Es necesario que los niños tengan libertad en sus juegos porque a través de ellos aprenden a pensar, a interpretar el mundo y a interactuar con él. La niña que no ejerce un rol activo, que no supera el universo narrativo propuesto jugando con su Barbie, es más susceptible de ser influida negativamente por los valores de consumo y de belleza perpetuados y transmitidos a través de la muñeca. 


\subsection{La muñeca Barbie en Internet}

Las empresas consideran a los niños un público consumidor que tiene deseos, necesidades y goza de autonomía en las relaciones de consumo. Para poder satisfacer las expectativas de los niños con eficacia, las marcas adaptan el discurso a ellos, teniendo en cuenta la capacidades intelectual y emocional de cada edad. Por eso, es imprescindible conocer las particularidades presentes en cada etapa de la vida de un niño para realizar una comunicación adecuada y eficaz.

Según Montigneaux (Montigneaux, 2003) el acto de consumir es un momento de disfrute y placer. En esta lógica también se incluye al público infantil que es cada vez más autónomo en los mecanismos de consumo. El niño, además de consumir de acuerdo con sus propios deseos y necesidades, también tiene una fuerte influencia en la compra de su familia.

Desde el punto de vista mercadotécnico, cuanto antes se dirijan a ellos, las estrategias de comunicación de las empresas, mejor, pues de esa forma la marca estará fidelizando a este público para que continúe consumiendo cuando sea adulto.

En este proceso de fidelización del público infantil, se destaca la importancia de los personajes elegidos como modelo. Los personajes son modelos inspiradores que ayudan a llevar a los niños a la condición de adultos, una vez que proponen modelos de comportamiento y formas de identificarse. Una característica común entre los niños, cuando se identifican con un personaje, es comportarse como él. De esta manera, se puede decir que una niña que sea fan de Barbie tiene una gran posibilidad de desear ser bella, famosa, rica, tener muchos vestidos, zapatos y accesorios. Desea ser la Barbie.

La marca utiliza el personaje para mejorar la comunicación con su público. En el caso de la marca Barbie, el personaje es capaz de transmitir las diferentes dimensiones de su identidad o las características de sus productos de una forma que sea comprensible para su público infantil mediante el uso de la emoción y de la imaginación. Barbie, por lo tanto, actúa como un vínculo entre los niños y la marca.

Roveri (Roveri, 2008) afirma que Barbie funciona como modelo de mediación entre dos mundos, ya que constituye un puente entre el presente de la niña y su futuro como adulta. Para que esa mediación sea posible, Montigneaux (Montigneaux, 2003) señala que el personaje es, en la mayoría de los casos, mayor que el niño, pues así es más fácil para él soñar e imaginar su futuro. 
La empresa Mattel ha desarrollado varias estrategias para difundir estos valores y para intentar satisfacer y aumentar el deseo de sus consumidoras que quieren ser como la muñeca. Muchas de estas estrategias se pueden encontrar en Internet a través de redes sociales y sitios Web para que las niñas vivan la experiencia de ser una Barbie.

Internet es una tecnología que posibilita una socialización en red que permite a sus usuarios atribuir significados a los mensajes e informaciones consumidas a partir de su individualidad, necesidades y motivaciones personales. La relación que se establece entre el niño e Internet es una experiencia muy diversificada, marcada por la organización no lineal de informaciones que le permite controlar el acceso a la Red a través de los intereses y prioridades individuales.

El niño interviene en la Red creando y modificando su manera de interaccionar así como la construcción de sus saberes.

Para los autores Kincheloe, Steinberg y Bricio (2004), el desarrollo de los medios de comunicación y la innovación tecnológica han ejercido una influencia considerable en la naturaleza de la infancia. Las grandes empresas han utilizado estas innovaciones en la tecnología junto con el desarrollo de los medios de comunicación para influir en la vida social y cultural de las personas en general y, según los autores, para moldear la conciencia de los niños.

La compañía de juguetes Mattel, por ejemplo, ha empleado las nuevas tecnologías para comunicarse con su público más joven con mayor eficacia. La marca Barbie está presente en diversos contextos: redes sociales, comunidades virtuales, juegos, sitios web, etc.

La estrategia que sigue Mattel es realizar una publicidad que no venda la muñeca Barbie como un solo producto, sino que expanda el nivel de la marca de juguetes. Así, una variedad de productos puede agregarse a Barbie: ropa, maquillaje, zapatos, artículos electrónicos, material escolar, etc. La marca transmite un concepto de belleza y juventud, una forma de vida.

La presencia de la marca en Internet es una manera de potenciar la divulgación de sus productos, así como una forma de mantener una relación más estrecha con su público. Desde su aparición, Barbie fue presentada como una muñeca que se cambia de ropa, haciendo que el cambio de trajes sea la esencia del juego.

En Internet pasa lo mismo. En la página Web de la marca, se incentiva a la niña a que 
La página Web se compone de diversos elementos necesarios para presentar el mundo de Barbie. Se divide en seis secciones: juegos, videos, armario, habitación, pelis, quiero ser. Además de estas secciones con contenidos dirigidos a los niños, hay otra en la página principal destinada a los padres que dirige a las acciones de la marca en redes sociales como Facebook y el sitio barbiecollector.com (orientado a adultos que son fans de la muñeca Barbie). En ambos casos, hay un mensaje avisando de la necesidad de permiso de los padres para que los niños puedan acceder al contenido de la marca dirigido a los adultos. En este artículo solo hemos analizado el contenido destinado al público infantil.

\section{METODOLOGÍA}

El corpus de este estudio lo compone la página Web de la marca Barbie. Los datos se generaron a través de la observación y recogida de material del sitio barbie.com y de la página de la marca Barbie en Facebook en el periodo de abril a junio de 2011. La metodología elegida para la realización de la investigación fue el análisis de contenido que según el autor (Piñuel Raigada 2002):

Se suele llamar análisis de contenido al conjunto de procedimientos interpretativos de productos comunicativos (mensajes, textos o discursos) que proceden de procesos singulares de comunicación previamente registrados, y que, basados en técnicas de medida, a veces cuantitativas (estadísticas basadas en a veces el recuento de unidades), a veces cualitativas (lógicas basadas en la combinación de categorías) tienen por objeto elaborar y procesar datos relevantes sobre las condiciones mismas en que se han producido aquellos textos, o sobre las condiciones que puedan darse para su empleo posterior (p. 2)

Para Minayo (2003), el análisis de contenido tiene como objetivo comprobar hipótesis o averiguar lo que el contenido manifiesto se propone. Es una técnica para identificar, basadas en datos, lo que se dice sobre un tema determinado. En esta investigación, el tema fue el consumo de los niños y las hipótesis del estudio fueron las siguientes:

La marca Barbie, en su página web, transmite valores centrados en el consumismo y en la valoración de la belleza estética.

\section{ANÁLISIS Y RESULTADOS}

\subsection{Análisis cuantitativo}

En el análisis cuantitativo se ha contabilizado palabras que se referían a la belleza y al 
Para que fueran más visibles, fueron adoptados algunos procedimientos: los verbos se pasaron al infinitivo (por ejemplo: compré está incluido en los resultados de comprar), los adjetivos y sustantivos se pasaron al femenino singular (por ejemplo: guapo (s) se incluye en los resultados como guapa), los resultados de la tabla fueron organizados en orden decreciente de frecuencia, palabras muy similares fueron combinadas en la misma palabra o expresión dominante, para organizarse de la siguiente manera:

a) Aspecto $/$ imagen $=$ Imagen

b) Atrevida / bonito / brillante / deslumbrante / elegante / encantadora / glamuroso / guapa / hermosa / linda / majestuosa / maravillosa / moderno / poderosa / vanidoso $=$ Adjetivos relacionados con la belleza

c) Desfile / modelo / pasarela = Desfile

d) Estilista / estilo / look = Estilo

e) Estrella / famosa = Famosa

f) Fashion / moda / tendencia = Moda

g) Probar $/$ vestir = Vestir

h) Peinar $/$ pelo $=$ Peinar

i) Bello $/$ belleza $=$ Belleza

j) Ropas / collar / anillo / bolso / falda / zapatos... = Trajes y accesorios

Por lo tanto, las palabras fueron agrupadas en las categorías: imagen, adjetivos relacionados con la belleza, desfile, estilo, famosa, moda, vestir, peinar, belleza, colección, compras, maquillaje, trajes y accesorios, princesa. Se ha obtenido el siguiente resultado:

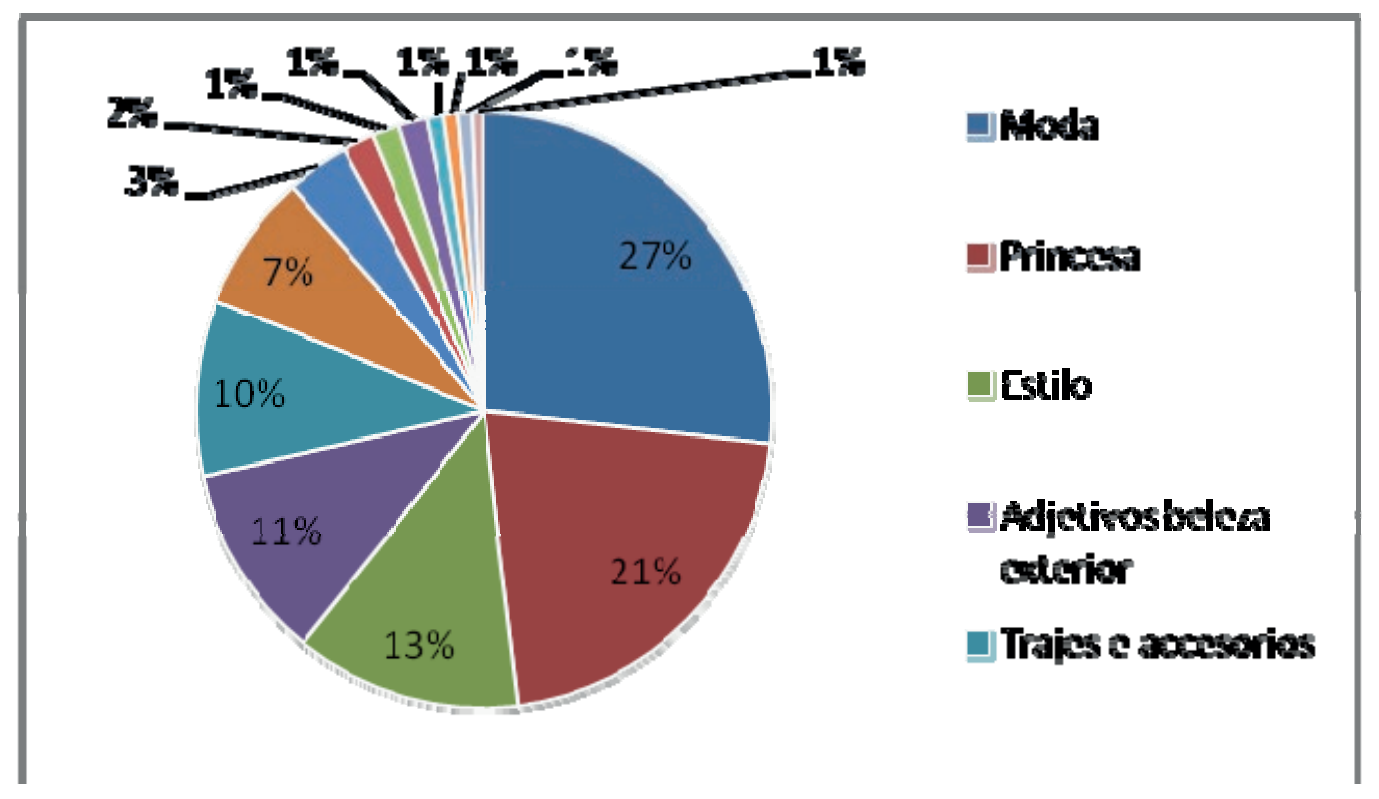


Tabla 1. Páginas web

\begin{tabular}{|l|l|}
\hline TOTAL DE LA PÁGINA WEB & \\
\hline Moda & 137 \\
\hline Princesa & 109 \\
\hline Estilo & 65 \\
\hline Adjetivos belleza & 55 \\
\hline Trajes e accesorios & 49 \\
\hline Famosa & 38 \\
\hline Desfile & 18 \\
\hline Maquillaje & 9 \\
\hline Belleza & 8 \\
\hline Imagen & 8 \\
\hline Vestir & 5 \\
\hline Peinado & 4 \\
\hline Comprar & 4 \\
\hline Colección & 3 \\
\hline
\end{tabular}

Visualizando la tabla y el gráfico anteriores se ha percibido que las palabras moda y princesa son las que más aparecen en la página web barbie.com. El énfasis en estas dos palabras demuestra como los mensajes del sitio están permeadas de consumismo y la valoración de la belleza exterior.

La palabra princesa se refiere a la idea de ser una mujer hermosa y dentro de los patrones socialmente aceptados. Según la Real Academia Española (RAE) significa:

a) Mujer que por sí goza o posee un Estado que tiene el título de principado.

b) Mujer del príncipe.

c) En España, título que da a la hija del rey, inmediata sucesora del reino".

Además del significado propuesto por la RAE, en el sentido figurado, la palabra princesa significa alguien que se destaca por su delicadeza y belleza. Este término se refiere también a cuentos de hadas tan presentes en la imaginación del niño y ampliamente utilizado por la marca Barbie como estrategia de marketing.

El personaje Barbie representó innumerables princesas de cuentos de hadas en películas y se lanzaron varias muñecas siguiendo la misma temática. La mayoría de las niñas crece con el sentimiento de ser la "princesa" de la familia y con el deseo de ser una verdadera princesa de cuentos de hadas. Siendo así, la página web 
La valoración de la apariencia física también se demuestra por la repetición de adjetivos como linda, maravillosa, encantadora, guapa, hermosa, majestuosa, entre otros. Estos términos tienen una representación significativa del 11\% del total. Esta misma idea también se ve reforzada por el uso de otros elementos que, aunque aparezcan en una frecuencia menor, deben ser considerados.

Es el caso de maquillaje, belleza, imagen y peinado. La página Web está llena de juegos que fomentan el cambio de imagen a través de un nuevo maquillaje y de bonitos peinados. El mensaje transmitido es que la chica debe siempre invertir en su aspecto físico para estar siempre hermosa. La belleza propuesta es artificial, lograda a través de cosméticos.

No hay evidencia de la valoración de la belleza natural. Para ser bella, la chica debe cambiar su imagen, usar maquillaje y un peinado con estilo.

Se ha observado que los mensajes están impregnados de los valores que fomentan el consumismo. La palabra más frecuente es moda, aparece 137 veces y representa el $27 \%$ del analizado. El término estilo aparece en la tercera posición (se menciona 65 veces). Todos los términos y las categorías incluidas en este párrafo están relacionados con el mundo de la moda.

Este estudio no ignora el hecho de que hay varios prejuicios en relación a la moda. En muchas ocasiones se ve como algo superficial e inútil. Sabemos que la moda no se limita sólo a esto, hay un contexto más amplio de implicaciones políticas y sociales. Sin embargo, es evidente que, en el sitio barbie.com, los términos relacionados con el mundo de la moda se refieren al mismo no como un reflejo de la evolución del comportamiento de la sociedad. Hacen referencia al mundo glamuroso de las celebridades con sus vestidos caros de diseñadores famosos.

Se ha discutido en la epígrafe 2 de este artículo la pertinencia de la muñeca Barbie como un soporte que permite, durante sus 52 años de existencia, observar la evolución de las mujeres y de las costumbres de nuestra sociedad. Pero el propósito de este estudio fue identificar las características de los mensajes transmitidos a las niñas a través del sitio Web barbie.com.

Analizando la tabla presentada anteriormente, se observa que la página Web del estudio está llena de expresiones típicas del universo de la moda. En muchos de los juegos del sitio se alude a las profesiones de modelo y diseñador de moda como profesiones que suelen estar vinculadas a la fama. Se constata ello en la frecuencia de las palabras que se refieren a famosa e desfile que son mencionadas, 
Otro punto a discutir es la categoría trajes y accesorios que representa el 10\% del total analizado, apareciendo 49 veces. Las palabras comprar, vestido y colección, aun teniendo una baja representatividad, merecen comentarios, pues al analizarlas junto con la categoría ropa y accesorio, que tiene una mayor frecuencia de palabras, permite una visión más clara del contexto.

El hecho es que la mayor parte de las actividades de la página Web se basan en el juego de vestir al personaje Barbie con diversos trajes y accesorios. El personaje virtual Barbie, así como la muñeca de juguete, no está destinada a tener una única ropa. Ella es una modelo famosa, entonces debe estar siempre de moda y tener una gran cantidad de ropa.

La niña que juega en la página Web tiene como una de las principales actividades elegir qué trajes pondrá a Barbie entre los muchos que la muñeca virtual posee. Con esto, se incentiva a las niñas a comprar y coleccionar una variedad de ropa no sólo para sus muñecas, sino también para ellas mismas, pues así serán hermosas como Barbie. Por tanto, la página Web de la marca Barbie transmite mensajes centrados en consumir objetos como una manera de ser socialmente aceptada.

Con el análisis de contenido de palabras hemos percibido que la página Web barbie.com presenta una gran cantidad de palabras que se refieren al consumo, así como a la belleza estética.

Algunas secciones del sitio tienen una mayor frecuencia de estos términos que las demás, pues es perceptible que cada parte del sitio presenta una faceta del personaje Barbie con el objetivo de establecer un vínculo entre la marca y el público infantil.

También se ha observado que la comparación de las palabras no ha sido suficiente para dar cuenta de la riqueza de los símbolos presentes en la página Web barbie.com. Fue necesario recurrir al análisis del discurso del personaje Barbie, buscando comprender cómo la muñeca virtual transmite los valores de la marca a sus consumidoras infantiles.

\subsection{Análisis cualitativo}

En el análisis cualitativo se han analizado fragmentos (frases, párrafos) escritos o dichos por el personaje Barbie. Se obtuvieron de la misma página Web utilizada en el análisis cuantitativo y no sufrieron alteraciones. Además del discurso del personaje Barbie, se observaron las actitudes, la postura y el escenario en que se inserta la muñeca en la página Web. Se estudiaron las secciones en las que Barbie se 
En según momento, se ha analizado el discurso de algunas fans de la muñeca en la página oficial de la marca en Facebook. Sólo las frases escritas por fans infantiles han hecho parte del análisis, una vez que el presente estudio tuvo el consumo infantil como tema.

Para identificar qué palabras fueron dichas por niñas, se utilizaron como criterios: las fotos de las fans y la presencia de errores gramaticales y / o de ortografía. Se ha preservado el estado original de las frases utilizadas en el análisis, entonces los posibles errores no fueron corregidos. Los nombres de las chicas no han sido citados en el trabajo. Los mensajes de la página de Facebook se han observado entre noviembre de 2010 y mayo de 2011.

\subsection{Análisis del discurso del personaje Barbie}

\section{Sección armario}

Al acceder a esta parte de la página Web, se ve la muñeca virtual Barbie actuando como se estuviera presentándose en un concierto. Cuando ella aparece en la escena, tiene las manos en la cintura, el escenario es iluminado con luces utilizadas en espectáculos o conciertos, se puede escuchar una canción alegre y ella convoca a sus fans diciendo:

\section{"Vamos a ponernos guapas".}

Después de decir esta frase, saca una de las manos de la cintura, chasquea los dedos y se le pone de nuevo con las manos en la cintura. Un gato aparece, maúlla y se sienta junto a la muñeca.

A pesar de Barbie estar en un escenario que se asemeja a un armario (lleno de ropas, zapatos, maquillaje, etc.), la postura de la muñeca es de una artista que se presenta ante una multitud de fans. La manera triunfal en la que aparece se asemeja a la entrada de un artista en un concierto. Sus manos en la cintura y sus piernas inclinadas recuerdan a una modelo en un desfile de moda. Su voz es dulce, agradable y acogedora.

Cuando invita a la niña a ser más bella, utiliza el verbo "vamos", lo que genera más proximidad, una vez que ella se incluye en el juego de ponerse guapa. Su actitud de chasquear los dedos cuando hablas, transmite la idea de que es posible ponerse guapa muy pronto, es sólo entrar en el mundo de Barbie y aprender sus trucos de belleza. 
Todas las calidades atribuidas a la rosa se consideran típicamente femeninas. La rosa simboliza la fuerza de los débiles, como el encanto y la amabilidad. En Romeo y Julieta, de Shakespeare, se lee [...] "Soy tan cortés como el color rosa". El rosa es y ha sido en todo los siglos el color típico de la cortesía, de la amabilidad. Y rosa es también la sensibilidad y la sentimentalidad. El rosa, mezcla de un color cálido y un color frío, simboliza las cualidades nobles del compromiso (Helle, 2004, pp. 213-214).

Por lo tanto, como el color rosa representa feminidad, amabilidad y sentimentalidad, es un color apropiado para ser asociado con la marca Barbie. En nuestra cultura este es un color que se utiliza sobre todo para las niñas, siendo así, el uso de tonos de rosa en la página Web barbie.com demuestra a que público la marca desea dirigirse y potencia una proximidad con él.

El uso del color rosa en el sitio barbie.com va más allá de la preocupación con la estética de la página Web, indica la intención de proponer actitudes y comportamientos que pueden ser generados por ese color. Se observa eso cuando se espera para cargar las páginas del sitio y aparece la frase “¡Piensa en rosa!”, en lugar de aparecer una barra con el porcentaje de carga. Esta es una frase imperativa llena de significados. La niña es invitada a creer que el mundo es de color rosa, es decir, sin maldad, mágico y bonito. "Pensar en rosa" es como se fuera la contraseña para entrar y vivir en el mundo de Barbie.

Además de la frase mencionada anteriormente, en la sección Armario, la muñeca Barbie se comunica con su público en el juego Maquillaje de Superestrella. Esta vez no transmite el mensaje oralmente, sino por escrito, diciendo: ${ }_{\text {NNecesito }}$ un nuevo estilismo para mi nueva sesión de fotos! ¡Crea un look deportivo, glamuroso o moderno! Haz clique en los botones de arriba o en "Jugar". Después aplica el color, córtame el pelo y crea un estilo".

En este texto, Barbie convoca a la niña que juega en su página Web para ayudarle a componer un nuevo visual para sacar unas fotos. Más una vez la muñeca invita al consumo de productos de belleza y ropa para poseer una apariencia que siga las tendencias de la moda y con las normas socialmente aceptadas.

\section{Sección habitación}

Barbie presenta la sección Habitación con esta frase:

"Puedes pasarte por mi habitación siempre que quieras". 
Las palabras son dichas después que termina un trecho de una canción envolvente y juvenil. Ella muestra una expresión de sorpresa como se alguien hubiera entrado de repente. Con una voz amable dice al visitante que le permite entrar en su habitación siempre que quiera. Siendo así, la niña que visita la página Web se siente integrada en el mundo de Barbie, ella puede ser amiga de la muñeca, compartir sus secretos y confidencias en su habitación. Una vez más la marca genera proximidad con el consumidor.

La muñeca aparece sentada en el suelo al lado del mismo gato que aparece en la sección Armario. Su habitación tiene una decoración típica de niña (paredes pintadas de color rosa, fotos de la familia y de su novio, objetos asociados con la feminidad como osito de peluche, flores, muñecas, cojines coloridos, material escolar, diario, etc.). Barbie pinta sus uñas, lo que demuestra su preocupación por la estética y sólo interrumpe la actividad para decir la frase comentada en el párrafo anterior.

Su vestimenta muestra un lado más infantil, ya que usa zapatillas de peluche de conejo, camisa y pantalones de color rosa. Incluso en un momento de intimidad en su habitación, lejos de la maquillaje y de los tacones que son elementos constantes en la vida de la muñeca, ella muestra preocupación con su apariencia en la escoja de la ropa, la forma de cruzar las piernas y como está su pelo arreglado. Barbie nunca renuncia a la belleza, incluso en los momentos íntimos desea estar bonita.

En esta sección, que representa su habitación, Barbie revela un poco de su intimidad. Ella cuenta un poco de su vida, presenta su familia que se compone por tres hermanas menores, un perro y un caballo. Se comunica con el público con un saludo muy íntimo: "Hola, amigos!". Enfatiza que se lleva bien con sus hermanas que son amigas muy cercanas, incluyendo el uso de letras mayúsculas para mostrar como ellas son especiales en su vida.

Hola, amiga! Me gustaría presentarte a tres personitas MUY especiales para mí! Son Skypper, Stacie y Chelsea, mis tres hermanas pequeñas, con las que me llevo genial. Cada una tiene su propia página aquí, donde podrás conocerlas mejor. Seguro que también te encantarán nuestras mascotas. Nuestro perro Taffy he estado conmigo desde que era un cachorrito, y Tawny es nuestro caballo, un animal supercariñoso. ¡Haz clic en su dibujo y te contaré más cosas sobre ellos! Besos, Barbie.

"La familia no solo está formada por personas. ¡Las mascotas también forman parte de ella! ¿Quieres conocer a mis mascotas Taffy y Tawny?". 
Barbie establece un vínculo con las niñas que le admiran cuando se comunica con ellas como se fuera una amiga. En una amistad cuando un amigo presenta su familia a otro amigo es porque esta amistad es ya lo suficientemente fuerte para permitir que ellos compartan información personal. Entonces, es clara la intención de la marca de establecer un relacionamiento a largo plazo con su público de consumidoras infantiles.

\section{Sección pelis}

En esta sección, Barbie se sienta en el borde de un lago justo en frente de la entrada de un palacio. El paisaje es muy colorido, con efectos de brillo en algunas partes, una mariposa vuela y el gato (presente en las dos secciones comentadas anteriormente) interactúa en el escenario tratando de atrapar un pez que nada en el lago. La mágica atmósfera se complementa con una canción instrumental y con el sonido de agua.

Barbie está sentada con las piernas cruzadas, haciendo burbujas de jabón, usa un delicado vestido lila, el pelo largo y liso como de una princesa. Con un tono de admiración, exclama mirando el palacio:

"¿Uau! jParece un mundo encantado!”.

Sus ojos muestran que ella no está haciendo la exclamación a sí misma. Cuando mira para el lado, da la impresión de que habla con la niña que acaba de acceder esta parte de la página Web. Sus gestos son muy delicados y un tanto artificiales, pues su postura no es de alguien que está relajada y que tiene actitudes naturales. Barbie se comporta como una persona que sabe que está siendo observada y admirada.

Al hacer clic para entrar en el palacio, Barbie aparece en un salón de lujo, decorado con muchos brillos y con el predominio del color dorado. Su figura surge de repente a través de una luz brillante en un toque de mágica y dice:

“ ¿Una corona para las ocasiones más elegantes!”.

Al finalizar de decir la frase, levanta la mano derecha, chasquea los dedos y aparece una corona sobre su cabeza. Está vestida con un elegante vestido en tonos lila con mucho brillo y guantes blancos. Tiene una postura recta y elegante, típica de una princesa.

Barbie asume diferentes roles en la página Web. Aparece con ropas modernas en la sección Armario, relajada en la sección Habitación y elegante en Pelis. La frase que ella 


\section{Sección juegos}

$\mathrm{Al}$ acceder a esta parte de la página Web, se ve Barbie mirando para la niña que le visita y diciendo la siguiente frase:

"¡Soy una experta en juegos!".

El escenario de esta sección es una verdadera habitación de juego. Barbie está sentada en un puf mientras juega videojuego y es observada por una amiga que está sentada a su frente. La muñeca viste jeans, camiseta, zapatillas y su pelo está recogido en dos trenzas. Tiene una postura relajada con gestos más naturales y espontáneos que en otras secciones de la página Web. Muestra que está atenta al juego y no asume ninguna pose de modelo.

Así como el resto de la página Web, hay predominio de los colores rosa y lila. Lo uso de esos colores, la no presencia masculina en el ambiente y los juegos claramente direccionados a niñas enfatizan cuál es el público de la marca.

Por cuarta vez aparece la figura del gato. Ahora él interactúa con el escenario, jugando con una máquina de chicle y haciendo un ruido cada vez que intenta sacar un chicle de la máquina. Entonces, se observó que la repetición de la imagen de ese animal en cuatro escenarios distintos busca generar familiaridad con el usuario que acceda a barbie.com.

\subsection{Análisis del discurso de las fans de Barbie en Facebook}

La página española de la marca Barbie en Facebook es una estrategia de aproximación e interacción con sus consumidores. La página tiene más de 6.000 fans que pueden ser adultos o niños, hombres o mujeres. En este trabajo, se ha analizado sólo los discursos de niñas fans de la muñeca Barbie, utilizando los criterios mencionados en el epígrafe anterior.

La página es un canal de comunicación directa con sus fans, utilizada para divulgar los nuevos productos, promociones y concursos. Hay una participación activa del público que se manifiesta mediante el envío de mensajes a Barbie, compartiendo sueños, opiniones, imágenes de sus colecciones de muñecas.

Observando los discursos de las niñas en el foro, se ha notado que la mayoría expresan las mismas ideas y sentimientos, siendo así, para una mejor organización del análisis, se ha dividido los discursos en cuatro bloques: creencia en la existencia 


\subsection{Creencia en la existencia real de la muñeca}

Barbie no es una muñeca como las demás. Ella tiene una familia, un trabajo, un novio, es decir, posee una biografía. Ultrapasó la condición de ser sólo un juguete, las niñas se sienten tan cerca de ella que algunas piensan que Barbie es real. Como se puede ver en las siguientes frases:

"que aces"

"la barbie tiene un cumpleaños?" "hola barbie donde vives"

"me encanta barbie quisiera conocerla"

"barbie mi madre quiere hablar

contigo por favor"

La página en Facebook es un lugar donde las fans infantiles de Barbie pueden comunicarse directamente con ella. Las frases anteriores muestran cómo la muñeca está presente en la vida de su público infantil. Barbie se presenta como una amiga de sus fans y la familiaridad generada es tan grande que las niñas necesitan de más información acerca de su personaje favorito, desean conocerla personalmente y que sus madres hablen con la muñeca.

No siempre las preguntas hechas a Barbie son contestadas, especialmente las relativas a la existencia real de la muñeca. La falta de respuestas es una manera de avivar la curiosidad de las niñas y de perpetuar el mito que rodea la muñeca.

"babie varias personas te escriben y tu respondes despues de semanas creo que deveria de ser inmediato"

La frase anterior representa la indignación de una niña por no tener todas las respuestas a sus preguntas y demuestra proximidad entre la muñeca y sus fans que poseen libertad incluso para criticar ciertas actitudes de Barbie.

\subsection{Demostración de afecto}

\section{“BARBIE ESTO ES PARA TI}

Bello, hermoso, sentimiento provocaste en mi vida, Amor, sentí cuando te conocí, eres mi favorita. Reí, y reí mientras jugaba contigo, mis problemas se esfumaban

Buenos, eran los tiempo que tu y yo estábamos juntas, inocente niña dulce Inocente niña dulce, junto a ti yo era, dejaste en mi corazón recuerdos inovidables Eres lo mejo ..." 
La mayoría de los mensajes de la página oficial de la marca Barbie en Facebook expresan admiración, afecto y simpatía por la muñeca. A continuación se puede ver algunas de ellas:

"barbie te amooooo

"si a mi me encanta BARBIE ES LA MEJOR" "barbie sos ermosa"

ERES ENCANTADORA" "que bonita muñeca :)"

"Barbie la muñeca es lindad, toda la muñeca es bonita, ermosa, muy bella, lindad, encantadora y tiene bonitos adornos".

Se observa que todas las frases se componen de adjetivos relacionados con la belleza de la muñeca. Las niñas utilizan sinónimos para decir lo mismo. Se nota que los adjetivos utilizados en los mensajes son semejantes a los identificados en el análisis cuantitativo de la página Web de la marca Barbie (presentado en el epígrafe 4.2). Por tanto, se observa que hay una identificación del público infantil con los mensajes transmitidos a través del sitio barbie.com.

"hola Qiero ser como tu tengo 11 añitos y yo quiero soñar como tu.!! Yo soi tu amiga favorita y tambn compartire con tus amigas para siempre"

"hola barbie yo quiero ser como tu y eres muy guapa"

Esas dos frases muestran que el personaje Barbie fue bien desarrollada por la marca, una vez que genera identificación con sus consumidoras infantiles. Los mensajes van más allá de la necesidad de expresar los sentimientos de las niñas por la muñeca. Ellas admiran la Barbie y quieren comportarse como ella.

"Hola a mi siempre me gusto las barbies desde que tenia 5 años hasta ahora que tengo 14 años no quiero crecer maas!!"

Esta declaración refleja la preocupación de una niña que consume el producto Barbie desde los 5 años, pero ahora tiene 14 años y dice que no quiere crecer, pues aún desea coleccionar muñecas Barbie. Para ella crecer significa la imposibilidad de seguir jugando con su muñeca preferida. Se observa en ese discurso una crisis de identificación con la marca. A pesar de la niña expresar que le encanta la muñeca, se siente mal porque ya tiene 14 años y tiene la percepción de que jugar con muñecas es algo no apropiado para su edad.

Para solucionar ese problema, la empresa Mattel trabaja con dos tipos de público: los jóvenes y los adultos. Las niñas crecen jugando con Barbie y cuando son adultas 


\subsection{Consumismo}

"Hola soy la fan numero 1 de todas las barbies las colecciono todas....tengo una repisa con 15 barbies las, colecciono todas como ya dije pero no importa q tipo de barbie sea igual me la compro obio....si mi mama y mi papa estan de acuerdo bueno un xao xao."

"soy fan numero uno de las barbies mi primera barbie la tube a los 5 añitos y tengo la barbie quero ser bailarina de ballet. Tengo 15 barbie, y 2 quen osea $q$ en total, tengo 17........ con mi mejor amiga belén aveses jugamos con ellas, y siempre escojemos ,las mismas........ osea la mas bonitas bueno chau".

En esos mensajes se revela cómo las consumidoras infantiles de Barbie valoran tener muchas muñecas. Las dos niñas autoras de las frases se consideran fans número 1 y exhiben con orgullo la cantidad de muñecas que posee. La primera enfatiza que no importa cuál es el modelo del juguete, lo que desea es comprar para completar su colección. A pesar de ella mencionar que necesita de la autorización de los padres para satisfacer su deseo de consumir cada nuevo modelo que la marca lanza.

que hermosa foto asta yo quiero tener toda la colecsion de las muñecas barbie tenes mucha suerte barbie yo tengo la pelicula de barbie moda magica en paris y me re encanto la pelicula tanbien me gustaron las adas magicas me encanto la pelicula y que ermoso bestido que tenias en la pelicula me encanto barbie sos la mejor....

\section{"yo quiero comprar barbie fasionistas"}

Esas declaraciones se refieren a modelos específicos de la muñeca Barbie. La primera se refiere la colección basada en la película Moda Mágica en Paris. La niña cuenta que ha gustado de la película, elogia el vestido que Barbie usa en la historia y comenta que quiere tener la colección completa de los productos lanzados en el tema de la película. En el segundo mensaje, la otra niña expresa que quiere comprar una de las muñecas de la colección Barbie Fashionistas, que es formada por seis muñecas que tienen estilos influenciados por las últimas tendencias de moda.

Es evidente el poder persuasivo de la publicidad de los productos de la marca Barbie. Todos los productos mencionados en los discursos como objetos de deseo son divulgados de manera lúdica a través de juegos en la página Web barbie.com.

\subsection{Sueños compartidos}


Bueno mi sueño bien soñadito es triunfar en la musica ser cantante pero ya joven, como a los 12 años o mi edad actual (10). Ese mismo es mi sueño cuando se dlo come a unos amigos se rieron mio diciendo que eso no se haria realidad.Pero no me importa lo q me digan nunca mi ILUSION, FE, ANELO y ESPERANZA se iran de mi por $\mathrm{q}$ se $\mathrm{q}$ DIOS como las personas q quieren ayudarme a realizarlo haran este sueño REALIDAD. y este es mi sueño por siempre y para siempre gracias por leer esto.

"quiero ser pediatra"

"hola tengo 11 años cuando ste grande me gustaria se chef o estrella de rock".

"hola yo y quiero ser niñera o mama cuando sea grande los chicos son mi vida para mi tengo

10 años y quisiera esto de grande!" "Ummm Yo Quiero Ser Modelo.....=)"

"Hola Barbie m'encanta tu pelo!! Tengo 10 años y cuando sea grande me encantaria ser Estrella de Pop!!"

Las frases anteriores muestran cómo las niñas se identifican con las profesiones que sirvieran de tema para las muñecas de la colección Barbie Quiero Ser. Las niñas admiran Barbie y se inspiran en sus actitudes.

Además de compartir sueños, las niñas comparten momentos íntimos, ansiedades y expectativas con la muñeca Barbie. Como se puede ver en esta declaración:

Hola, tengo 8 años y soy tu fans desde que tengo, tres años y mi madre desde los 5 años y ahora estamos separadas, porq ella esta alla en España y yo aquí en ecuador, y yo quiero ser bailarina y estar junto a mi madre gracias Barbie, eres parte fundamental en nuestras vidas, has creado felicidad inocencia, y eres un gran lazo de amor $u$ amistad en mi familia, te quiero muakkkkkk DIOS TE BENDIGA

En el mensaje anterior, se puede leer la historia de una niña que revela que Barbie representa un vínculo entre ella y su madre que está lejos. El amor de ambas por la muñeca hace con que se ellas sientan más próximas una de la otra.

\section{CONCLUSIONES}

En este estudio se ha buscado comprender cómo la empresa Mattel utiliza el 
Al final del análisis se ha constatado que la página Web comunica por medio de contenidos de entretenimiento valores relacionados con el consumo y la excesiva apreciación de la belleza estética.

El personaje Barbie actúa como agente mediador. Funciona como un transmisor de la identidad de la marca, estableciendo un vínculo con su público de consumidoras infantiles. La muñeca mantiene una relación con sus fans en el sitio barbie.com de manera que la niña que accede a la página Web no sea tratada como una consumidora más de entre las muchas que existen. Barbie comunica sus mensajes de manera que cada niña sea reconocida como única. Las declaraciones, las actitudes y la forma en que se comporta generan proximidad con su público e identificación con los valores de la marca.

La repetición de elementos (color rosa, logomarca, mascota, comportamiento del personaje, etc.) genera familiaridad $y$, en consecuencia, facilita el reconocimiento de los productos y servicios ofrecidos por la marca. Las actividades de entretenimiento predominan en la página Web y también funcionan como un mecanismo de aproximación entre personaje y público.

Por tanto, la marca Barbie usa la muñeca virtual en el sitio barbie.com para estrechar la relación con sus consumidores infantiles y establecer una comunicación que sea inteligible, adecuada y eficiente.

El análisis del discurso de la fans infantiles de Barbie en Facebook ha permitido medir el grado de identificación de las niñas con el personaje Barbie. Se ha observado que las niñas se identifican con el comportamiento y las actitudes de la muñeca y de esa manera comprenden los valores transmitidos por la marca. Valores que están impregnados con el consumismo y el culto a la belleza estética.

Se ha notado en los mensajes en Facebook que, de alguna manera, Barbie ejerce un rol positivo para las niñas que proyectan su vida adulta a través de la muñeca. Sin embargo, ya que Barbie sirve como modelo de inspiración para muchas niñas, es necesario que se reflexione acerca del contenido de los mensajes transmitidos por ella para que la muñeca no resulte en un modelo nocivo para el desarrollo de las niñas que la consumen.

Valores como independencia, solidaridad, actitud crítica frente la vida, reflexión sobre el acto de consumir no son fácilmente asociados con la imagen de Barbie en Internet y se puede decir que la falta de esos valores se convierte en una representación no realista de ella. 
El hecho es que cuando se trata de niños, hay una fuerte relación entre infancia e Internet $\mathrm{y}$, a pesar de la dificultad existente en la comprensión de cómo Internet actúa en el cotidiano de los niños, es necesario seguir haciendo esfuerzos para entender este universo. Debemos ser conscientes de qué tipo de sitios los niños están expuestos. Una página Web que tenga varios elementos lúdicos no es obligatoriamente algo beneficioso para los niños.

No hay que olvidar que las herramientas lúdicas y de entretenimiento, muchas veces, son utilizadas por las marcas para atraer la atención del público infantil. Por tanto, hay una necesidad urgente de una educación para el consumo. Sólo los niños conscientes de las relaciones de consumo estarán protegidos de los abusos cometidos por las empresas, incluso en Internet.

\section{REFERENCIAS}

Almeida, D.; Barbosa, L. de \& Heberle, V. (2006). As bonecas da contemporaneidade: representações da identidade feminina. Trabajo presentado en Anais do VII Seminário Fazendo Gênero.

Domínguez Pereira, Ma del C.; \& Juste Pino, Margarita R. (2005). Globalización e educación en valores: contribucións educativas dende o fenómeno social da boneca Barbie. Revista galega do ensino, 47 de noviembre de 2005: 1103-1126.

Helle, Eva (2004). Psicología del color: cómo actúan los colores sobre los sentimientos y la razón. Barcelona: Editorial Gustavo, SA.

Kincheloe, J. L; Steinberg, S. R; Bricio, G. \& Japiassú, Eduardo (2004). Cultura infantil: a construção corporativa da infância. Rio de Janeiro: Civilização Brasileira.

Lévy, P. (1999). Cibercultura. São Paulo: Editora 34.

Minayo, M.C. De S. (2003). Pesquisa Social: Teoria, Método e Criatividade. Rio de Janeiro: Vozes.

Montigneaux, N. (2003). Público-alvo: crianças. Rio de Janeiro: Ed. Campus.

Raigada Piñuel, J. L. (2002). Epistemología, metodología y técnicas del análisis de contenido" en Estudios de Sociolingüística. Universidad Complutense de Madrid.

Roveri, F. Th. (2008). Barbie: tudo o que você quer ser... ou considerações sobre a educação 
Silva, O. (2002). El análisis del discurso según Van Dijik y los estudios de la Comunicación. Razón y Palabra, 26. Recuperado el 25 de mayo de 2011, de http://www.razonypalabra.org.mx/anteriores/n26/osilva.html.

Wolf, N. (1992). O mito da beleza: como as imagens de beleza são usadas contra as mulheres. Rio de Janeiro: Rocco.

\section{Pâmela Saunders Uchôa Craveiro}

Actualmente es doctoranda en Comunicación en la Universidad de Vigo. Investiga sobre el nuevo sistema mediático y lúdico que altera y modifica la identidad cultural del jugar. Posee un Máster en Investigación en Comunicación por la Universidad de Vigo (2011) y graduación en comunicación social (publicidad y propaganda) por la Universidad Federal de Ceará (2010). Actúa principalmente en los siguientes temas: infancia, internet y consumo. 